\title{
Association between Helicobacter pylori seropositivity and NAD(P)H:quinone oxidoreductase 1 (NQO1) C609T polymorphism observed in outpatients and health checkup examinees
}

\author{
Yasuyuki Goto ${ }^{1,2}$, Nobuyuki Hamajima ${ }^{1}$, Hiroyuki Honda ${ }^{3}$, Keitaro Matsuo ${ }^{4}$, Kazuhito Yamamoto ${ }^{1}$, \\ Akiko Tamakoshi ${ }^{1}$, Takafumi Ando ${ }^{2}$, and Hidemi Goto ${ }^{2}$ \\ ${ }^{1}$ Department of Preventive Medicine / Biostatistics and Medical Decision Making, Nagoya University Graduate School of Medicine, \\ 65 Tsurumai-cho, Showa-ku, Nagoya 466-8550, Japan \\ ${ }^{2}$ Department of Gastroenterology, Nagoya University Graduate School of Medicine, Nagoya, Japan \\ ${ }^{3}$ Department of Biotechnology, School of Engineering, Nagoya University, Nagoya, Japan \\ ${ }^{4}$ Division of Epidemiology and Prevention, Aichi Cancer Center Research Institute, Nagoya, Japan
}

\begin{abstract}
Background. Significant associations of Helicobacter pylori (H. pylori) seropositivity have been found with several host polymorphisms. This study investigated the associations of functional polymorphisms of the NQO1, GSTM1, and GSTT1 genes of detoxification enzymes, with the seropositivity, as well as with pepsinogen levels, as markers of gastric atrophy.

Methods. The subjects were 241 noncancer outpatients who had participated in an $H$. pylori eradication program (HPE) at Aichi Cancer Center Hospital, and 465 health checkup examinees in Nagoya (HCE). The NQO1 C609T, GSTM1, and GSTT1 polymorphisms were determined by triplex polymerase chain reaction with confronting two-pair primers (PCR-CTPP).

Results. The sex- and age-group-adjusted odds ratio (OR) of NQO1 C/C for $\mathrm{H}$. pylori seropositivity relative to $\mathrm{T} / \mathrm{T}$ was highly significant; OR, 1.92; 95\% confidence interval $(95 \%$ CI), 1.22-3.03. The ORs of the GSTM1 present type and GSTT1 present type for $H$. pylori seropositivity were not significant; OR, 0.87; 95\% CI, 0.64-1.20 and OR, 1.14; 95\% $\mathrm{CI}, 0.83-1.57$, respectively. The association of the $\mathrm{NQO1} \mathrm{C} / \mathrm{C}$ genotype with $H$. pylori seropositivity was observed only for never-smokers; OR, 2.25; 95\% CI, 1.33-3.79. The genotypes of the NQO1, GSTM1, and GSTT1 genes were not associated with the development of atrophic gastritis among the $\boldsymbol{H}$. pylori-seropositive subjects.

Conclusion. This is the first study to report a significant association of the $\mathrm{NQO1} \mathrm{C609T}$ polymorphism with $\mathrm{H}$. pylori seropositivity. The biological mechanism explaining the significant association with the seropositivity remains to be elucidated.
\end{abstract}

Key words NQO1 • Polymorphism - Helicobacter pylori · Atrophic gastritis

Offprint requests to: Y. Goto

Received: May 18, 2004 / Accepted: October 18, 2004

\section{Introduction}

Gastric cancer is the second most frequent cancer in the world, accounting for a large proportion of cancer cases in Asia, Latin America, and some countries in Europe [1]. The etiology of gastric cancer is not well established, although nutritional, microbial, and genetic factors have been suggested to be involved in a multistep and multifactorial process [2]. Helicobacter pylori has been reported to play a specific role in the development of atrophic gastritis that represents the most recognized pathway in multistep intestinal-type gastric carcinogenesis [3-5]. H. pylori infection is considered to occur primarily in childhood, through an oral-oral or fecaloral route, mainly from the family [6-8], depending on sanitary conditions [7]. Because some individuals who are exposed are not infected with the bacterium, it is assumed that host factors have an important role in the infection and its maintenance. Recently, associations between HLA types [9] and polymorphisms of the secretor gene [10], Lewis gene [10], interleukin $1 B$ (IL$1 B)$ gene [11-14], myeloperoxidase (MPO) gene [15], tumor necrosis factor $A(T N F-A)$ gene [16,17], and the TCRBV6S1 gene [18] and $H$. pylori seropositivity have been reported.

Nicotinamide adenore dinucleotide phosphate, reduced $(\mathrm{NAD}(\mathrm{P}) \mathrm{H})$ :quinone oxidoreductase 1 (NQO1) is a cytosolic obligate two-electron reductase characterized by its capacity for utilizing NADH or NADPH as a reducing cofacor $[19,20]$. NQO1 prevents the generation of semiquinone free radical and reactive oxygen species, thus protecting cells from oxidative damage [21]. On the other hand, NQO1 activates nitrosoaromatic compounds and heterocyclic amines in tobacco smoke and food, which may work to induce carcinogenesis $[22,23]$. The activity level of the NQO1 enzyme is determined by a single C-to-T substitution at 609 (exon 
6) of the NQO1 cDNA that causes a Pro187Ser aminoacid change [24]. While the enzyme encoded by the $\mathrm{C} / \mathrm{C}$ genotype has full enzyme activity, that encoded by the T/T genotype has complete lack of activity. The enzyme activity for the $\mathrm{C} / \mathrm{T}$ genotype decreases to approximately one-third of that for the $\mathrm{C} / \mathrm{C}$ genotype [24-27]. Associations between the $\mathrm{T} / \mathrm{T}$ genotype and various cancers, including renal [28], urothelial [28], colorectal [29], cutaneous basal cell carcinomas [30], and pediatric leukaemia [31] have been reported in previous studies.

Glutathione S-transferase (GST) $\mu$ and GST $\theta$ are enzymes involved in the conjugation of reactive electrophiles to soluble glutathione and, therefore, they play an important role in the detoxification of endogeneous and exogeneous toxicants, including heterocyclic amines [32]. Individuals who are carriers of homozygous deletions in the GSTM1 or GSTT1 gene may have an impaired ability to metabolically eliminate carcinogenic compounds and may, therefore, be at an increased cancer risk [33].

This study aimed to evaluate the associations of polymorphisms of the NQO1, GSTM1, and GSTT1 genes with $H$. pylori seropositivity and atrophic gastritis. We also investigated the effect of interactions between the NQO1, GSTM1, and GSTT1 genes, and smoking on the risk of $H$. pylori seropositivity.

\section{Subjects and methods}

\section{Study subjects}

Two sets of subject data were used for the present analysis. The first subject group included 241 noncancer outpatients (118 male and 123 female), aged 39 to 69 years, who participated in an H. pylori eradication program (HPE) at Aichi Cancer Center Hospital between March and December, 1999. The group included 97 participants who were receiving medication for 107 diseases (23 gastric/duodenal ulcers; another 23, socalled gastritis; and 61 miscellaneous diseases) [34] and who participated in the program without knowing their infection status.

The second group of subjects included 468 health checkup examinees (128 male and 340 female), aged 32 to 85 years, who attented a health checkup (HCE) program supported by the Nagoya Municipal Government in Nagoya, in August and September, 2000. The examinees were inhabitants of the west ward of Nagoya City, who had had no chance to attend health checkups at their workplaces [13]. Out of 489 examinees invited to participate in the study, 468 agreed to provide their blood for genetic tests, along with the requested information. However, 3 subjects did not allow their blood samples to be used for DNA extraction; Therefore, the HCE group for this study included 465 subjects. Eleven participants had a cancer history, including 2 with gastric cancer. The subjects in both groups were each classified into two groups; neversmokers and ever-smokers (including current smokers and former smokers). The study protocols were approved by the Ethics Committee of the Aichi Cancer Center, and were subject to the draft version of the guidelines for research on the human genome, issued on March 29, 2001, by the collaboration of three Japanese ministries.

\section{Tests for $\mathrm{H}$. pylori antibody and pepsinogens}

An anti-HP IgG antibody test, high-molecular weight Campylobacter-associated-protein (HM-CAP) enzyme-linked immunosorbent assay (ELISA; Enteric Products, Westbury, NY, USA) was conducted by SRL (Tokyo) to detect $H$. pylori-infected participants. The sensitivity of the HM-CAP is reported to be $98.7 \%$, with a specificity of $100 \%$, in the United States [35], though the sensitivity was not so high for Japanese [36]. An ELISA value of 2.3 or over was regarded as indicating H. pylori infection-positive status. Concentrations of pepsinogens I and II (PG1 and PG2) in sera from the HPE subjects and plasma from the HCE subjects were measured by radioimmunoassay, using a commercially available kit (Dinabot, Tokyo, Japan). Atrophic gastritis was defined as PG1 less than $70 \mathrm{ng} / \mathrm{ml}$ and a PG1/ PG2 ratio of less than 3 .

\section{Genotyping}

DNA was extracted from the buffy coat fraction with a Qiagen QIAamp DNA Blood Mini Kit (Qiagen, Valencia, CA, USA). Genotyping of the NQO1 C609T, GSTM1, and GSTT1 genes was conducted by polymerase chain reaction with confronting two-pair primers (PCR-CTPP). The primers and PCR conditions were described previously [37].

\section{Statistical analysis}

The strength of associations between $H$. pylori seropositivity and polymorphisms of the NQO1, GSTM1, or GSTT1 genes were measured as odds ratios (ORs). ORs, adjusted for sex, age, and subject group, with 95\% confidence intervals (CIs), were calculated using logistic regression analysis. Hardy-Weinberg equilibrium was tested for the NQO1 C609T polymorphism. The equilibrium test was not applicable for the GSTM1 and GSTT1 genes, because the homozygous and heterozygous genotypes with the "present" allele are not distinguished. These calculations were performed 
Table 1. Genotype distribution of NQO1 C609T, GSTM1, and GSTT1 genes according to subject group

\begin{tabular}{|c|c|c|c|c|c|c|}
\hline \multirow[b]{2}{*}{ Polymorphism } & \multicolumn{2}{|c|}{$\mathrm{HPE}^{\mathrm{a}}$} & \multicolumn{2}{|c|}{$\mathrm{HCE}^{\mathrm{b}}$} & \multicolumn{2}{|c|}{ Total } \\
\hline & $n(\%)$ & $\mathrm{HP}+\%$ & $n(\%)$ & $\mathrm{HP}+\%$ & $n(\%)$ & $\mathrm{HP}+\%$ \\
\hline \multicolumn{7}{|l|}{ NOO1 C609T } \\
\hline $\mathrm{T} / \mathrm{T}$ & $48(19.2)$ & 54.2 & $83(18.6)$ & 48.2 & $131(19.0)$ & 50.4 \\
\hline $\mathrm{C} / \mathrm{T}$ & $107(44.4)$ & 58.9 & $210(47.1)$ & 57.1 & $317(46.0)$ & 57.7 \\
\hline $\mathrm{C} / \mathrm{C}$ & $86(35.7)$ & 72.1 & $153(34.3)$ & 55.6 & $239(35.0)$ & 61.5 \\
\hline \multicolumn{7}{|l|}{ GSTM1 } \\
\hline Null & $125(53.4)$ & 64.8 & $207(46.4)$ & 56.0 & $332(48.8)$ & 59.3 \\
\hline Present & 109 (46.6) & 60.6 & $239(53.6)$ & 54.0 & $348(51.2)$ & 56.0 \\
\hline \multicolumn{7}{|l|}{ GSTT1 } \\
\hline Null & $103(44.0)$ & 61.2 & $215(48.2)$ & 53.3 & $318(46.8)$ & 55.7 \\
\hline Present & $131(56.0)$ & 64.2 & $231(51.8)$ & 56.7 & $362(53.2)$ & 59.4 \\
\hline
\end{tabular}

HPE, Participants in a Helicobacter pylori eradication program; HCE, health checkup examinees; HP+\%, H. pylori-seropositive percentage

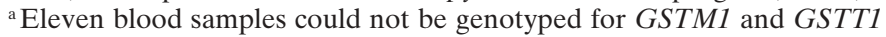

${ }^{\mathrm{b}}$ Nineteen blood samples could not be genotyped

Table 2. Sex- and age-adjusted odds ratios (ORs) and $95 \%$ confidence intervals (95\% CIs) for Helicobacter pylori seropositivity according to the NQO1 C609T, GSTM1, and GSTT1 genotypes in the HPE, and HCE groups, and the groups combined

\begin{tabular}{|c|c|c|c|c|c|c|}
\hline \multirow[b]{2}{*}{ Polymorphism } & \multicolumn{2}{|c|}{ HPE } & \multicolumn{2}{|c|}{$\mathrm{HCE}$} & \multicolumn{2}{|c|}{ Combined } \\
\hline & OR & $95 \% \mathrm{CI}$ & OR & $95 \% \mathrm{CI}$ & OR & $95 \% \mathrm{CI}$ \\
\hline \multicolumn{7}{|l|}{ NQO1 C609T } \\
\hline $\mathrm{T} / \mathrm{T}$ & 1 & Reference & 1 & Reference & 1 & Reference \\
\hline $\mathrm{C} / \mathrm{T}$ & 1.13 & $0.55-2.33$ & 1.57 & $0.92-2.68$ & 1.43 & $0.93-2.19$ \\
\hline $\mathrm{C} / \mathrm{C}$ & 2.42 & $1.11-5.29$ & 1.70 & $0.96-2.98$ & 1.92 & $1.22-3.03$ \\
\hline $\mathrm{C} / \mathrm{T}+\mathrm{C} / \mathrm{C}$ & 1.56 & $0.80-3.06$ & 1.62 & $0.98-2.68$ & 1.62 & $1.08-2.41$ \\
\hline \multicolumn{7}{|l|}{ GSTM1 } \\
\hline Null & 1 & Reference & 1 & Reference & 1 & Reference \\
\hline Present & 0.84 & $0.48-1.46$ & 0.90 & $0.61-1.33$ & 0.87 & $0.64-1.20$ \\
\hline \multicolumn{7}{|l|}{ GSTT1 } \\
\hline Null & 1 & Reference & 1 & Reference & 1 & Reference \\
\hline Present & 1.17 & $0.67-2.05$ & 1.14 & $0.77-1.67$ & 1.14 & $0.83-1.57$ \\
\hline
\end{tabular}

HPE, Participants in a Helicobacter pylori eradication program; HCE, health checkup examinees; combined, both groups combined, adjusted for sex, age, and group

with a computer program (STATA Version 7; STATA, College Station, TX, USA).

\section{Results}

The characteristics of the study subjects were described previously [13,34]. The genotype distributions of the NQO1, GSTM1, and GSTT1 genes are shown in Table 1. The distribution of the NQO1 gene was in HardyWeinberg equilibrium for HPE $\left(\chi^{2}=1.93 ; P=0.17\right)$, HCE $\left(\chi^{2}=0.64 ; P=0.43\right)$ and both groups combined $\left(\chi^{2}=2.14 ; P=0.14\right)$. The genotype distributions in the two datasets (HPE and HCE) were similar. As described in our previous articles $[13,34], H$. pylori seropositivity tended to increase with age and was highest for the more-than-60-year age group in any study group.
The seropositivity rate was highest for those with the $N Q O 1 \mathrm{C} / \mathrm{C}$ in the HPE group, and for those with the $N Q O 1 \mathrm{C} / \mathrm{T}$ in the HCE group. When the two groups were combined, the seropositivity rate for those with the $N Q O 1 \mathrm{C} / \mathrm{C}$ was highest. There were no substantial differences in the seropositivity rates between the genotypes of the GSTM1 and GSTT1 genes.

Table 2 shows the sex- and age-adjusted ORs and $95 \%$ CIs for $H$. pylori seropositivity according to the genotypes of the NQO1, GSTM1, and GSTT1 genes in the HPE and HCE groups, and both groups combined. The increased OR of the NQO1 C/C for H. pylori seropositivity relative to $\mathrm{T} / \mathrm{T}$ was statistically significant in the HPE group, and marginally significant in the HCE group. The ORs of the GSTM1 present type and GSTT1 present type for $H$. pylori seropositivity were not significant in either the HPE or the HCE group. When both 
Table 3. Sex- and age-group-adjusted odds ratios (ORs) and $95 \%$ confidence intervals (95\% CIs) for Helicobacter pylori seropositivity according to the NQO1 C609T, GSTM1, and GSTT1 genotypes in never-smokers and ever-smokers

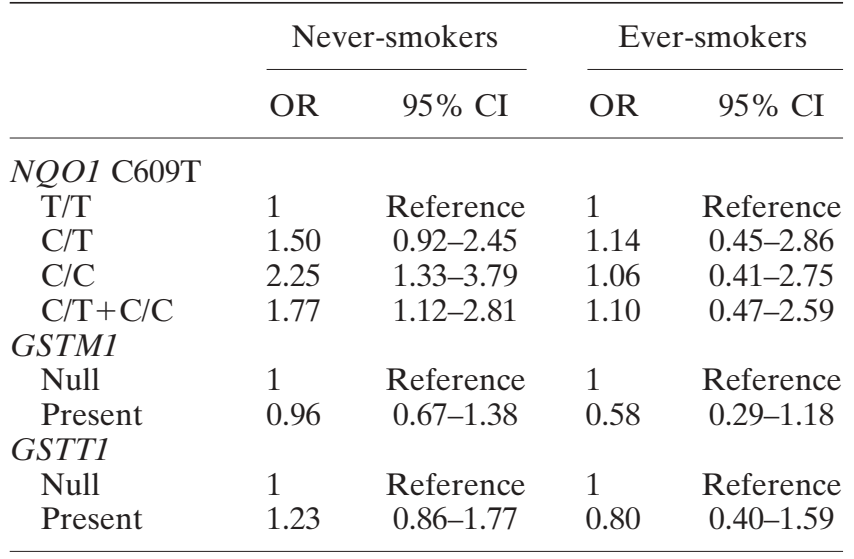

datasets were combined, the ORs of the $N Q O 1 \mathrm{C} / \mathrm{C}$ and $\mathrm{C} / \mathrm{C}+\mathrm{T} / \mathrm{T}$ genotypes were 1.92 (95\% CI, 1.22-3.03) and 1.62 (95\% CI, 1.08-2.41), respectively. The combined ORs for the GSTM1 and GSTT1 genes were not statistically significant.

The sex- and age-group-adjusted ORs and 95\% CIs for $H$. pylori seropositivity according to the genotypes of the NQO1, GSTM1, and GSTT1 genes in neversmokers and ever-smokers are shown in Table 3. In the never-smokers, the ORs of the $N Q O 1 \mathrm{C} / \mathrm{C}$ and $\mathrm{C} / \mathrm{C}+$ $\mathrm{C} / \mathrm{T}$ genotypes were statistically significant for association with $H$. pylori positivity (OR, 2.25; 95\% CI, 1.333.79 and OR, 1.77; 95\% CI, 1.12-2.81, respectively), while the corresponding ORs were not significant among the ever-smokers. The OR for the interaction between the $N Q O 1 \mathrm{C} / \mathrm{C}$ genotype and smoking was 0.55 (95\% CI, 0.25-1.19). The ORs of the GSTM1 present type and the GSTT1 present type for H. pylori seropositivity were not significant in either never-smokers or ever-smokers.

We additionally examined the ORs of the genotypes of the NQO1, GSTM1, and GSTT1 genes for atrophic gastritis (Table 4). The ORs for the NQO1 $\mathrm{C} / \mathrm{C}, \mathrm{C} / \mathrm{T}$, and $\mathrm{C} / \mathrm{C}+\mathrm{C} / \mathrm{T}$ for atrophic gastritis were not significant among $H$. pylori-seropositivite participants. Similar to the findings above, the ORs for the genotypes of the GSTM1 and GSTT1 genes were also not significant.

\section{Discussion}

This study found that $N Q O 1609 \mathrm{C} / \mathrm{C}$ with full enzyme activity was a high-risk genotype for $H$. pylori seropositivity, relative to $609 \mathrm{~T} / \mathrm{T}$, with lack of enzyme activity, especially for never-smokers. The present types of
Table 4. Sex- and age-group-adjusted odds ratios (ORs) and $95 \%$ confidence intervals (95\% CIs) of the NQO1 C609T, GSTM1, and GSTT1 genotypes for atrophic gastritis (AG) among Helicobacter pylori-seropositive participants

\begin{tabular}{lrllc}
\hline & $n$ & AG\% & OR & $95 \%$ CI \\
\hline NQO1 C609T & & & & \\
T/T & 66 & 48.5 & 1 & Reference \\
C/T & 183 & 53.6 & 1.25 & $0.71-2.20$ \\
C/C & 147 & 53.1 & 1.23 & $0.68-2.21$ \\
C/T+C/C & 330 & 53.3 & 1.24 & $0.73-2.11$ \\
GSTM1 & & & & \\
$\quad$ Null & 197 & 48.3 & 1 & Reference \\
Present & 195 & 56.4 & 1.35 & $0.90-2.02$ \\
GSTT1 & & & & \\
$\quad$ Null & 177 & 52.4 & 1 & Reference \\
Present & 215 & 51.2 & 0.87 & $0.58-1.30$ \\
\hline AG\%, Percent & & & &
\end{tabular}

$\mathrm{AG} \%$, Percentage of atrophic gastritis

GSTM1 and GSTT1 genes, with similar detoxification enzyme activity, were not associated with $H$. pylori seropositivity. Gastric atrophy among the H. pyloriseropositive participants was not associated with any genotypes. To our knowledge, there have been no reports concerning the associations between these genetic polymorphisms and $H$. pylori seropositivity. Because inconsistent findings are not rare in the field of association studies on polymorphisms, two datasets were studied; one from outpatients who participated in an $H$. pylori eradication program (HPE) and the other from health checkup examinees in the same area (HCE). Although the association was marginally significant for the HCE group, fairly consistent findings were observed. We have been screening dozens of polymorphisms to find associations with $H$. pylori seropositivity in our exploratory analysis [38], where the nominal $P$ value was not corrected in view of multiple comparisons, similarly to other exploratory studies. Because an exploratory study cannot confirm the nature of an association, confirmatory studies are required.

If an association exists, the biological mechanisms supporting the association should be considered. However, there have been no reports on the biological roles of NQO1 in bacterial infection. Because the GSTM1 and GSTT1 genes were not associated with H. pylori seropositivity, the function of NQO1 as a detoxification enzyme may not be relevant to the observed association.

To date, the factors found to favor persistent $H$. pylori infection have been those relating to gastric acid secretion. It is considered that gastric acid inhibition leads to $H$. pylori distribution to the corpus [39], making a favorable condition for $H$. pylori to survive in the stomach lumen. The associations of $H$. pylori seropositivity with the polymorphisms of genes encoding interleukin (IL)-1 $\beta$ and tumor necrosis factor (TNF)- $\alpha$, 
potent acid inhibitors [40], support this hypothesis. It is not clear whether the two-electron reduction by NQO1 has a certain function in gastric acid secretion.

The biological reason that the association was marked only for the never-smokers is unclear. It is well known that chemicals in smoke induce many substances, including inflammation-related markers [41,42]. The associations between H. pylori seropositivity and the genotypes of the $I L-1 B$ gene [11-14] and the $M P O$ gene [15] were stronger among smokers than among nonsmokers in the HPE dataset. This study found that the association of $H$. pylori seropositivity with the $N Q O 1 \mathrm{C} / \mathrm{C}$ genotype was stronger in the neversmokers, suggesting that smoking can cancel the effect of NQO1 activity in the gastric mucosa. Because the interaction between smoking and $N Q O 1 \mathrm{C} / \mathrm{C}$ was not significant (OR, 0.55; 95\% CI, 0.25-1.19), the difference in the OR between never-smokers and ever-smokers could have occurred by chance. Confirmation by both epidemiologic and biological approaches seems to be required.

In conclusion, our data suggested that $N Q O 1$ gene polymorphism influences $H$. pylori seropositivity. Although epidemiologic findings, lacking information on the biological mechanism, could be the first step to elucidate the relationship between host factors and outcome, biological evidence will be required. Studies of a larger size are needed to confirm the association between this gene polymorphism and $H$. pylori seropositivity.

Acknowledgments The authors are grateful to Dr. Nobuyuki Katsuda for his field work assistance and Ms. Yoko Mitsuda and Ms. Mayumi Kato for their technical assistance.

\section{References}

1. Parkin DM, Pisani P, Ferlay J. Global cancer statistics. CA Cancer J Clin 1999;49:33-64.

2. Correa P. Human gastric carcinogenesis: a multistep and multifactorial process - First American Cancer Society award lecture on cancer epidemiology and prevention. Cancer Res 1992;52:673540.

3. Covacci A, Telford JL, Del Giudice G, Parsonnet J, Rappuoli R. Helicobacter pylori virulence and genetic geography. Science 1999;284:1328-33.

4. Crabtree JE, Taylor JD, Wyatt JI, Heatley RV, Shallcross TM, Tompkins DS, et al. Mucosal IgA recognition of Helicobacter pylori 120-kDa protein, peptic ulceration and gastric pathology. Lancet 1991;338:332-5.

5. Kuipers EJ, Perez-Perez GI, Meuwissen SG, Blaser MJ. Helicobacter pylori and atrophic gastritis: importance of the cagA status. J Natl Cancer Inst 1995;87:1777-80.

6. Goodman K, Correa P. The transmission of Helicobacter pylori. A critical review of the evidence. Int J Epidemiol 1995;24:875-87.

7. Brown LM. Helicobacter pylori: epidemiology and routes of transmission. Epidemiol Rev 2000;22:283-97.
8. Tindberg $\mathrm{Y}$, Bengtsson $\mathrm{C}$, Granath F, Blennow M, Nyrén O, Granström M. Helicobacter pylori infection in Swedish school children: lack of evidence of child-child transmission outside the family. Gastroenterology 2001;121:310-16.

9. Go MF. What are the host factors that place an individual at risk for Helicobacter pylori-associated disease? Gastroenterology 1997:13:S15-20.

10. Ikehara Y, Nishihara S, Yasutomi H, Kitamura T, Matsuo K, Shimizu N, et al. Polymorphisms of two fucosyltransferase genes (Lewis and secretor genes) involving type I Lewis antigens are associated with the presence of anti-Helicobacter pylori IgG antibody. Cancer Epidemiol Biomarkers Prev 2001;10:9719.

11. Hamajima N, Matsuo K, Saito T, Tajima K, Okuma K, Yamao K, et al. Interleukin 1 polymorphisms, lifestyle factors, and Helicobacter pylori infection. Jpn J Cancer Res 2001;92:383-9.

12. Hamajima $\mathrm{N}$, Ito $\mathrm{H}$, Matsuo $\mathrm{K}$, Tajima $\mathrm{K}$, Tominaga $\mathrm{S}$. Helicobacter pylori seropositivity, Interleukin $1 \mathrm{~B}$ polymorphism, and smoking among first-visit outpatients. Asian Pac J Cancer Prev 2002;3:23-8.

13. Katsuda N, Hamajima N, Matsuo K, Saito T, Ito LS, Inoue M, et al. Association between the interleukin 1B (C-31T) polymorphism and Helicobacter pylori infection in health checkup examinees (in Japanese). Jpn J Public Health 2001;48:604-12.

14. Uno M, Hamajima N, Ito LS, Oba SM, Marie SKN, Shinjo SK, et al. Helicobacter pylori seropositivity and $I L-1 B$ C-31T polymorphism among Japanese Brazilians. Int J Mol Med 2002;10: 321-6.

15. Hamajima N, Matsuo K, Suzuki T, Nakamura T, Matsuura A, Tajima K, et al. Low expression myeloperoxidase genotype negatively associated with Helicobacter pylori infection. Jpn J Cancer Res 2001;92:488-93.

16. Yea SS, Yang YI, Jang WH, Lee YJ, Bae H-S, Paik K-H. Association between TNF-alpha promoter polymorphism and Helicobacter pylori cagA subtype infection. J Clin Pathol 2001;54: 703-6.

17. Hamajima N, Shibata A, Katsuda N, Matsuo K, Ito H, Saito T, et al. Subjects with $T N A-A-857 T T$ and $-1031 T T$ genotypes showed the highest Helicobacter pylori seropositive rate compared with those with other genotypes. Gastric Cancer 2003;6:230-6.

18. Kunstmann E, Hardt C, Elitok E, Harder M, Suerbaum S, Peitz $\mathrm{U}$, et al. The nonfunctional allele TCRBV6S1B is strongly associated with Helicobacter pylori infection. Infect Immun 2000;68: 6493-5.

19. Ernster L. DT-diaphorase. Methods Enzymol 1967;10:309-17.

20. Winski SL, Koutalos Y, Bentley DL, Ross D. Subcellular localization of $\mathrm{NAD}(\mathrm{P}) \mathrm{H}$ : quinone oxidoreductase 1 in human cancer cells. Cancer Res 2002;62:1420-4.

21. Rauth AM, Goldberg Z, Misra V. DT-diaphorase: possible roles in cancer chemotherapy and carcinogenesis. Oncol Res 1997;9: 339-49.

22. De Flora S, Bennicelli C, D'Agostini F, Izzotti A, Camoirano A. Cytosolic activation of aromatic and heterocyclin amines. Inhibition by dicoumarol and enhancement in viral hepatitis B. Environ Health Perspect 1994;102:69-74.

23. Chen S, Knox R, Lewis AD, Friedlos F, Workman P, Deng PS, et al. Catalytic properties of $\mathrm{NAD}(\mathrm{P}) \mathrm{H}$ :quinone acceptor oxidoreductase: study involving mouse, human, and mouse-rat chimeric enzymes. Mol Pharmacol 1995;47:934-6.

24. Kuehl BL, Paterson JW, Peacock JW, Paterson MC, Rauth AM. Presence of a heterozygous substitution and its relationship to DT-diaphorase activity. Br J Cancer 1995;72:555-61.

25. Larson RA, Wang Y, Banerjee M, Wiemels J, Hartfold C, Lebeau $\mathrm{MM}$, et al. Prevalence of the inactivating $609 \mathrm{C} \rightarrow \mathrm{T}$ polymorphism in the $\mathrm{NAD}(\mathrm{P}) \mathrm{H}$ : quinone oxidoreductase (NQO1) gene in patients with primary and therapy-related myeloid leukemia. Blood 1999:94:803-7.

26. Moran JL, Siegel D, Ross D. A potential mechanism underlying the increased susceptibility of individuals with a polymorphism in 
NAD(P)H: quinone oxidoreductase $1(N Q O 1)$ to benzene toxicity. Proc Natl Acad Sci USA 1999;96:8150-5.

27. Smith M. Benzene, NQO1, and genetic susceptibility to cancer. Proc Natl Acad Sci USA 1999;96:7624-6.

28. Schulz WA, Krummeck A, Rösinger I, Eickelmann P, Neuhaus C, Ebert T, et al. Increased frequency of a null-allele for NAD $(\mathrm{P}) \mathrm{H}$ : quinone oxidoreductase in patients with urological malignancies. Pharmacogenetics 1997;7:235-9.

29. Lafuente MJ, Casterad X, Trias M, Ascaso C, Molina R, Ballesta $\mathrm{A}$, et al. NAD(P)H:quinone oxidoreductase-dependent risk for colorectal cancer and its association with the presence of K-ras mutations in tumors. Carcinogenesis 2000;21:1813-19.

30. Clairmont A, Sies H, Ramachandran S, Lear JT, Smith AG, Bowers $\mathrm{B}$, et al. Association of $\mathrm{NAD}(\mathrm{P}) \mathrm{H}$ :quinone oxidoreductase (NQO1) null with numbers of basal cell carcinomas: use of a multivariate model to rank the relative importance of this polymorphism and those at other relevant loci. Carcinogenesis 1990;20:1235-40.

31. Wiemels JL, Pagnamenta A, Taylor GM, Eden OB, Alexander FE, Greaves MF, et al. A lack of a functional NAD $(\mathrm{P}) \mathrm{H}$ : quinone oxidoreductase allele is selectively associated with pediatric leukemias that have MLL fusions. Cancer Res 1999;59:4095-9.

32. Lin D, Meyer DJ, Ketterer B, Lang NP, Kadlubar FF. Effects of human and rat glutathione S-transferases on the covalent DNA binding of the $\mathrm{N}$-acetoxy derivatives of heterocyclic amine carcinogens in vitro: a possible mechanism of organ specificity in their carcinogenesis. Cancer Res 1994;54:4920-6.

33. Timothy RR. Molecular epidemiology of the human glutathione S-transferase genotypes GSTM1 and GSTT1 in cancer susceptibility. Cancer Epidemiol Biomarkers Prev 1997;6:733-43.
34. Hamajima N, Katsuda N, Matsuo K, Saito T, Ito LS, Ando M, et al. Smoking habit and interleukin $l B C-31 T$ polymorphism. J Epidemiol 2001;11:120-5.

35. Evans D, Evans DG, Graham DY, Klein PD. A sensitive and specific serologic test for detection of Campylobacter pylori infection. Gastroenterology 1989;96:1004-8.

36. Matsuo K, Hamajima N, Tominaga S, Suzuki T, Nakamura T, Matsuura A, et al. Helicobacter pylori IgG antibody test established in the United States showed a substantially lower sensitivity for Japanese population. Am J Gastroenterol 2000;95:1597-8.

37. Kawase H, Hamajima N, Tamakoshi A, Wakai K, Toshiko S, Tajima K. Triple polymerase chain reaction with confronting twopair primer (PCR-CTPP) for NQO1 C609T, GSTM1 and GSTT1 polymorphisms: a convenient genotyping method. Asian Pac J Cancer Prev 2003;4:67-70.

38. Hamajima N. Persistent Helicobacter pylori infection and genetic polymorphisms of the host. Nagoya J Med Sci 2003;66: 103-17.

39. El-Omar EM. The importance of interleukin 1B in Helicobacter pylori associated disease. Gut 2001;48:743-7.

40. Beles IL, Calam J. Interleukin 1 beta and tumour necrosis factor alpha inhibit acid secretion in cultured rabbit parietal cells by multiple pathways. Gut 1998;42:227-34.

41. Mizia-Stec K, Zahorska-Markiewicz B, Ga̧sior Z. Cigarette smoking and inflammatory indices in coronary disease. Int $\mathrm{J}$ Cardiol 2004;93:169-74.

42. De Maat MPM, Pietersma A, Kofflard M, Sluiter W, Kluft C. Association of plasma fibrinogen levels with coronary artery disease, smoking and inflammatory markers. Atherosclerosis 1996; 121:185-91. 